\title{
Taxonomic analysis of soil phytopathogenic mycocomplexes of different varieties of faba beans in the Central Black Earth Region of the Russian Federation
}

\author{
Yulia Kurkina $^{1 *}$, and Ngo T. Z. Kieu Isabelle ${ }^{2}$ \\ ${ }^{1}$ Belgorod State National Research University, 308015, Belgorod, Russia \\ ${ }^{2}$ Department of Science and Technology of Quang Ngai province, 202A, Truong Chinh road, Quang \\ Ngai City, Vietnam
}

\begin{abstract}
The species composition and structure of soil complexes of micromycetes under faba beans were studied. The indices of the frequency of occurrence and abundance of microscopic fungi species in soils under ten varieties of faba beans were analyzed in comparison with the control soil (pure fallow). The control revealed 20 species of micromycetes from 10 genera. The species from 16 genera were identified under the varieties of beans in the soils. Most micromycetes belong to the Ascomycota division (classes Dothideomycetes, Eurotiomycetes, Saccharomycetes, and Sordariomycetes). In the soil of faba beans, the number of micromycete propagules is significantly higher $(30.6 \pm 2.5$ thousand CFU / g soil) than in the control $(12.5 \pm 2.3$ thousand $\mathrm{CFU} / \mathrm{g})$. The biodiversity of micromycete complexes in the control soil was maximal (Pielu index 0.75). An increase in the dominance index under the studied varieties of beans (Simpson's index 0.09-0.24) was noted in comparison with the control soil, with a dominance index of 0.07 . Phytopathogenic species of micromycetes were found: fungi Ascochyta fabae, Alternaria tenuissima, Cladosporium herbarum, Fusarium culmorum, F. oxysporum, F. solani, and Ulocladium botrytis.
\end{abstract}

Keywords: micromycetes, taxonomic analysis, faba beans, soil phytopathogenic.

\section{Introduction}

Faba beans (Vicia faba L. var. major Harz) are a valuable food crop: green fruits, seeds and young leaves are used for food, both fresh and boiled, dry, frozen, canned. Due to the significant content of carbohydrates, vitamins $\mathrm{A}, \mathrm{B}_{1}, \mathrm{~B}_{2}, \mathrm{C}, \mathrm{PP}$, organic acids, mineral salts of potassium, phosphorus, calcium and magnesium, taste and calorie content, the culture has long been used in dietary nutrition all over the world [1]. The plants have great bioresource potential and should take a leading place in the development of food technologies that provide a more complete and in-depth processing of raw materials, taking

* Corresponding author:kurkina@bsu.edu.ru 
into account the chemical composition and biological value $[2,3]$. Faba beans also have an important agrotechnical value, they actively fix nitrogen from the soil and from the atmosphere, and surpass peas in the efficiency of symbiotic nitrogen fixation, assimilating about $315 \mathrm{~kg}$ / ha of nitrogen during 110 days of vegetation [4]. Because of this, culture is one of the best predecessors. Leaving behind in the soil up to $50-80 \mathrm{~kg} /$ ha of nitrogen, it can become an integral link in the biologization of agriculture and crop production by reducing the technogenic load on the agrocenosis [5].

The presence of a whole complex of pathogens in the agrocenosis is the main problem when growing any crop. To successfully cultivate legumes, it is necessary to take into account biological factors such as microscopic fungi, which, according to our data, can cause $[6,7]$, up to $90 \%$ of all plant diseases. Fungal diseases can lead to yield losses of up to $59 \%$, while reducing the total sugar content, the amount of chlorophyll and ascorbic acid in plants, and the amount of protein in seeds decreases by $3-5 \%$. Bean seeds can be affected by various pathogens and are one of the sources of transmission of dangerous mycoses. With a strong infection, the seeds lose their germination, and with a weak one, the energy of seed germination decreases and the development of plants is delayed, which causes sparse crops, the quantity and quality of the crop suffers [8]. Consequently, the study of the features of individual components of biocenoses with legumes is still insufficiently studied, but an urgent problem. The aim of this work was to analyze the species composition and structure of soil complexes of micromycetes under varieties of broad beans.

\section{Materials and methods}

The studies were carried out on the basis of the Department of Biotechnology and Microbiology of the Belgorod State National Research University ("BelSU"). The experimental objects of research were 10 varieties of vegetable beans from the collection of the authors, grown in small-plot experiments in 2009-2019. In field experiments, seeds of the 1st reproduction of the varieties "Aquadul", "White large-fruited", "Belorusskie", "Bobchinskie", "Leader", "Pink Flamingo", "Velena", "Green Jack", "Russian Black" and "Royal Harvest"

Bean plants were grown in an ordinary way (according to the scheme 20x45 cm) on accounting plots with an area of $5 \mathrm{~m} 2$ in 2 replicates. The experiments were carried out according to the method of B.A. Dospekhova [9]. The soil on the experimental plot is ordinary chernozem. In terms of granulometric composition - medium loam (contains up to $30-45 \%$ of physical clay), in structure - fine lumpy. Active soil acidity ( $\mathrm{pH}$ of water extract) 7.6. Agrotechnical measures were carried out manually. The beans were sown in the second half of April. Seeds were sown into the soil to a depth of 6-8 cm. After sowing, manual watering was carried out to ensure the conditions for seed swelling. Crop care consisted of timely care for seedlings and young plants, their hilling to ensure plant resistance to winds, weeding, watering, inter-row loosening, post-sowing control of crust, pests and diseases. Harvesting was carried out when the seeds were fully ripe. The variety of weather conditions during the years of the study should have contributed to a more complete study of vegetable beans plants in the Belgorod region.

The materials for mycological research in the laboratory were soil samples collected from the root zone (to a depth of $25-30 \mathrm{~cm}$ ) from under 10 plants of each variety. Steaming soil (pure fallow), sampled from experimental plots between plots at 10 different points, served as a control. The isolation of soil fungi was carried out by the Waksman soil dilution method followed by deep sowing in dense nutrient media [10]. The inoculations were incubated at $23 \pm 2{ }^{\circ} \mathrm{C}$ in a thermostat for 5-14 days. The grown colonies were seeded into a test tube on a nutrient medium. The quantitative registration of fungal colonies was 
carried out on the 7-14th day. To study the micromorphology and identify the isolated fungi, a light optical microscope "Micromed-2" and a DCM 310 video eyepiece were used.

The taxonomic affiliation of fungi was determined by the totality of cultural and morphological characters using special guidelines $[11,12]$. The indices of the frequency of occurrence and abundance of species were analyzed when determining the characteristics of the structure of complexes of soil micromycetes [13]. Species with a spatial and temporal occurrence of more than $60 \%$ were considered dominant, more than $30 \%$ were frequent, and a spatial occurrence of less than $30 \%$, and a temporal occurrence of more than $30 \%$, were considered to be dominant. Incidental species had a frequency of less than $30 \%$. To assess the similarity between the complexes of soil micromycetes under the bean varieties, the Jaccard coefficient was used; the degree of dominance of species in the complex was assessed using the Simpson index; To determine the biodiversity of micromycete complexes in the rhizosphere, the Pielou (E) evenness index was used [14]. Statistical analysis of the results obtained in laboratory and field experiments included calculations of the arithmetic mean, errors of the mean using the methods of variation statistics in the Excel computer program. To assess the significance of differences, the Student's t test was used.

\section{Results and discussions}

It was revealed that the species diversity of the mycobiota of the control soil (pure fallow, steaming soil) was described by 10 genera, including 20 species. Under the studied varieties of faba beans, 33 species from 16 genera were identified. In terms of species composition, the most represented were the genera Penicillium Link (10 species), Aspergillus P. Micheliex Haller (7 species) and Fusarium Link (3 species). The genus Rhizopus Ehrenb is represented by 2 species, the remaining 12 genera (Acremonium, Alternaria, Ascochyta, Bipolaris, Candida, Cladosporium, Cunninghamella, Mucor, Myrothecium, Nigrospora, Trichoderma, Ulocladium) included one species each.

Taxonomic analysis showed that the majority of micromycetes in the soil under vegetable beans belong to the Ascomycota division and 4 classes Dothideomycetes, Eurotiomycetes, Saccharomycetes, and Sordariomycetes, 7 orders and 12 families. From the class Sordariomycetes, the Hypocreales order is represented by 3 families Hypocreaceae (1 genus, 1 species), Nectriaceae (1 genus, 3 species), Incertaesedis (3 genera, 3 species). The class Dothideomycetes is represented by 2 orders Pleosporales and Capnodiales, 3 families Pleosporaceae (3 genera, 3 species), Didymellaceae (1 genus, 1 species) and Davidiellaceae (1 genus, 2 species). The class Eurotiomycetes included the order Eurotiales with the family Trichocomaceae ( 2 genera) and the class Saccharomycetes is represented by the order Saccharomycetales with the family Saccharomycetaceae (1 genus, 1 species). The Zygomycota division was characterized by only one class Zygomycetes and one order Mucorales with 3 families: Mucoraceae (1 genus, 2 species), Rhizopodaceae, and Cunninghamellaceae (1 genus and 1 species each).

The species A. tenuissima (Fr.) Wiltshire, A. fumigatus Fresen, A. nidulans (Eidam) G. Winter, A. niger Tieghem, A. ochraceus Wilh., A. terreus Thom, A. ustus (Bainier) Thom \& Church, C. herbarum (Pers.) Link, F. oxysporum Schltdl., F. solani (Mart.) Sacc., $M$. strictus Hagem, M. verrucaria (Alb. \& Schwein.) Ditmar, N. oryzae Berk. et Br., P. cyclopium Westling, P. decumbens Thom, P. meleagrinum, Rh. microsporus Tiegh, $R h$. stolonifer (Ehrenb.) Lindt, T. viride Pers. The list of soil sample species in the cultivation of 10 varieties of $\mathrm{V}$. faba compared to the control soil was more by 14 species: A. strictum $\mathrm{W}$. Gams, A. fabae, A. flavus, B. australensis (MB Ellis) Tsuda \& Ueyama, C. krusei (Castellani) Berkhout, C. echinulata (Thaxter) Thaxter, F. culmorum (Sm.) Sacc, P. 
digitatum (Pers.) Sacc., P. funiculosum Thom, P. humuli, P. lanosum Westling, P. martensii Biourge, $P$. purpurogenum Stoll, $U$. botrytis Preuss.

In the mycocomplex of the control soil, A. niger and Rh. microsporus were identified as dominant species, 6 species were frequent: A. fumigates, A. ochraceus, A. ustus, $F$. oxysporum, F. solani, $N$. oryzae. Two species are identified as rare: $C$. herbarum and $R h$. stolonifer. Nine species were classified as random (A. tenuissima, A. nidulans, A. terreus, $M$. strictus, $M$. verrucaria, $P$. cyclopium, $P$. decumbens, $P$. meleagrinum, and $T$. viride). In the complex of micromycetes of the vegetable bean variety "Aquadul", 16 species were found (A. tenuissima, A. fumigates, A. niger, A. ochraceus, A. ustus, C. herbarum, $C$. echinulata, $F$. culmorum, $F$. oxysporum, $F$ solani, $P$. funiculosum, $P$. lanosum, $P$. meleagrinum, $P$. purpurogenum, $R$. microsporus, $T$. viride) with a dominant core similar to the control soil.

The variety "White large-fruited" revealed 13 species (A. niger, A. ustus, $B$. australiensis, F. culmorum, F. oxysporum, F. solani, M. verrucaria, $N$. oryzae, $P$. decumbens, P. martensii, P. purpurogenum, Rh. Microsporus, Rh. stolonifer), with an increase in the rank of $F$. oxysporum fungi to the dominant species. In the composition of the mycocomplex under the variety "Belorusskie", 12 species were identified (A. flavus, $A$. fumigates, A. niger, A. ustus, C. krusei, C. herbarum, F. oxysporum, F. solani, N. oryzae, P. purpurogenum, Rh. microsporus, Rh. stolonifer). The species C. krusei was found in the rank of frequent, which was not registered in the soil of control, and in the rank of rare - $A$. flavus. It should be noted that other species decreased the rank compared to the control soil.

The highest species diversity was observed in the soil samples selected under the "Bobchinskie" variety (18 species). There were 12 common species with the control soil, which were found in different ranks (A. niger, A. ochraceus, A. terreus, A. ustus, $C$. herbarum, F. oxysporum, F. solani, M. strictus, N. oryzae, P. cyclopium, Rh. Microsporus, T. viride) and 6 species distinguishing this complex from the control one (A. strictum, $A$. flavus, C. echinulata, F. culmorum, P. funiculosum, $P$. humuli). The soil mycobiota of the "Velena" cultivar, with a similar control dominant core, consisted of 19 species $(A$. strictum, A. nidulans, A. niger, A. terreus, A. ustus, B. australiensis, C. krusei, $F$. oxysporum, F solani, M. strictus, N. oryzae, P. cyclopium, P. digitatum, P. humuli, $P$. purpurogenum, Rh microsporus, Rh. Stolonifer, T. viride). Most types of the complex have increased their rank in comparison with the control samples.

In the soil mycocomplex of the "Green Jack" variety, out of 14 detected species, 10 species were common with the complex of micromycetes of the steaming soil (A. nidulans, A. niger, A. ustus, F. oxysporum, M. verrucaria, N. oryzae, P. cyclopium, Rh. Microsporus, Rh. Stolonifer, T. viride) and distinguished 4 species (Fusarium culmorum, P. digitatum, $P$. humuli, $P$. purpurogenum). The phytotopathogen $F$. oxysporum increased the rank to dominant. The soil of the "Leader" cultivar contains 15 species (A. tenuissima, A. fabae, $A$. fumigates, A. nidulans, A. niger, A. terreus, A. ustus, F. culmorum, F. oxysporum, $M$. verrucaria, N. oryzae, P. meleagrinum, P. purpurogenum, Rh. Microsporus, T. viride) and, as in the control soil, $A$. niger was dominant. Six frequent species were found as a result of an increase in the rank of the frequency of occurrence of random species $A$. nidulans, $A$. terreus, rare species $F$. oxysporum, N.oryzae, $T$. viride in the control soil. A phytopathogenic species $A$. fabae was found.

The soil mycocomplex of the "Pink Flamingo" cultivar contains 12 species $(A$. fumigatus, A. niger, A. ustus, F. culmorum, F. oxysporum, F. solani, M. strictus, $P$. purpurogenum, Rh. Microsporus, $T$. viride, U. botrytis), with a similar control dominant nucleus. Twelve species were found in soil samples of the "Russkie Chernye" variety $(A$. flavus, A. niger, A. ochraceus, A. ustus, C. krusei, F. oxysporum, F. solani, M. verrucaria, $N$. oryzae, $P$. martensii, $R h$. microsporus, $T$. viride) and rare species made up the majority of the mycocomplex ( $78 \%$ of the total number of typical species) 
The soil complex of micromycetes of the "Royal Harvest" variety is represented by 14 species (A. strictum, A. flavus, A. niger, A. ochraceus, A. ustus, F. culmorum, $F$. oxysporum, F. solani, M. verrucaria, N. oryzae, P. cyclopium, P. humuli, Rh. microsporus, T. viride) and the largest number of species common with steaming soil (11 species, except for A. strictum, A. flavus, and F. culmorum). The phytopathoene $F$. oxysporum dominated under the plants. Thus, in the mycocomplexes under the varieties of vegetable beans, species of different ranks of frequency of occurrence developed, which were not found in steaming soil (A. strictum, A. graminea, A. flavus, B. australensis, C. krusei, C.echinulata, $F$. culmorum, $P$. digitatum, $P$. funiculosum, $P$. humuli, $P$. lanosum, $P$. martensii $P$. purpurogenum, $P$. rugulosum, $U$. botrytis). This can be explained by the fact that the different composition of exudates in the root zone of soils under plants contributes to the development of different types of microorganisms. The fungi A. fabae, found only in the soil under the Leader cultivar and $U$. botrytis under the "Pink Flamingo" cultivar, turned out to be cultivar-specific. Probably, these types of phytopathogenic fungi were introduced into the soil with sowing material. The species A. niger, A. ustus, F. oxysporum, and Rhizopus microsporus were found in all soil samples.

It should be noted that the amount of micromycete propagules in the soil of vegetable beans is much higher than in the control soil. The total number of micromycetes averaged $30.6 \pm 2.5$ thousand CFU / g soil, which is $12.5 \pm 2.3$ thousand CFU / g higher than in the control soil. At the same time, the soil mycocomplex of the "Russian Black" variety had the smallest abundance, and the highest values were observed in the "Aquadul" and "Belorusskie" varieties (45.8 thousand CFU / g soil). The number of micromycetes under the studied varieties in ascending order is as follows: control soil (18.1 \pm 1.2 thousand CFU / g soil) - "Russian black" (18.4 \pm 2.1$)$ - "Royal Harvest" $(19.4 \pm 2.6)$ - "Pink flamingo"(19.8 \pm 1.7$)$ - "Bobchinsky"* $(22.1 \pm 2.4)$ - "Leader"* $(23.9 \pm 2.0)$ - "White largefruited"* $(38.8 \pm 2.2)$ - "Velena"* $(39.8 \pm 4.1)$ - "Green Jack"* $(40.1 \pm 3.2)$ - "Aquadul"* $(45.8 \pm 1.5)$ - "Belarusian"* $(45.8 \pm 3.4$ thousand CFU / g soil) $(*$ - P0.05 with control).

In the complexes of micromycetes under varieties of vegetable beans, the proportion of typical species increased by $7.7-47 \%$ and their abundance increased by $4-28 \%$ compared to the control soil. Among the genus Fusarium, there are phytopathogenic representatives that are the causative agents of mycoses in beans (Wolfgang et al., 2008). When analyzing the soil mycobiota of the studied beans, 3 species were found: F. culmorum, $F$. oxysporum, $F$. solani. F. oxysporum was found in the rank of dominant and frequent in all soil samples, including control. In the rank of rare, the species was found only under the variety "Pink Flamingo".

Fungi $F$. solani was found in the rank of frequent only under the variety "Bobchinskie", as a rare and occasional species - under 5 and 2 varieties, respectively. Fungi $F$. culmorum were random in soil samples under 4 cultivars, and in the rank of rare species were found under 3 cultivars. It should be noted that among the typical species in the control soil "Royal Harvest", "Aquadul", "Leader" was dominated by representatives of the genus Penicillium (34-91\%). The conditionally pathogenic fungus C. krusei was highly represented in the mycocomplex under the variety "Belorusskie" (69\%). Of the typical species, species of the genus Rhizopus were found, which developed in all soil samples, and their representation above 30\% was noted under the varieties "White large-fruited" (54\%), "Green Jack" (55\%).

Diversity, dominance, and evenness were analyzed using the Shannon, Simpson, and Pielu indices (table 1).

It was found that the biodiversity of micromycete complexes in the control soil was maximum (Shannon's index $H^{\prime}=2.67$, Pielou's index $E=0.75$ ). In the soil complex of micromycetes under the "Bobchinskie" variety, the highest biodiversity index $\mathrm{H} '=2.43$ was revealed, under the "Velena" variety - $\mathrm{H}^{\prime}=2.13$. In the complex of soil micromycetes with 
beans, the proportion of random species decreased and, at the same time, the degree of dominance of typical species increased. An increase in the dominance index under the studied varieties of beans (Simpson's index 0.09-0.24) was noted in comparison with the control soil, with the dominance index $\mathrm{D}=0.07$

Table 1. Characteristics of soil mycocomplexes of vegetable beans varieties

\begin{tabular}{|c|c|c|c|}
\hline \multirow{2}{*}{ Name of varieties } & \multicolumn{3}{|c|}{ Indexes } \\
\cline { 2 - 4 } & Shannon & Simpson & Pielu \\
\hline Control & $2.67 \pm 0.02$ & $0.07 \pm 0.01$ & $0.75 \pm 0.02$ \\
\hline Aquadul & $2.20 \pm 0.02$ & $0.16 \pm 0.01$ & $0.78 \pm 0.02$ \\
\hline Belorusskie & $2.02 \pm 0.01$ & $0.15 \pm 0.02$ & $0.79 \pm 0.02$ \\
\hline White large-fruited & $1.65 \pm 0.01$ & $0.11 \pm 0.01$ & $0.57 \pm 0.01$ \\
\hline Bobchinskie & $2.43 \pm 0.01$ & $0.13 \pm 0.02$ & $0.79 \pm 0.03$ \\
\hline Velena & $2.13 \pm 0.02$ & $0.15 \pm 0.01$ & $0.37 \pm 0.01$ \\
\hline Green Jack & $1.75 \pm 0.01$ & $0.16 \pm 0.01$ & $0.64 \pm 0.01$ \\
\hline Leader & $2.01 \pm 0.02$ & $0.09 \pm 0.01$ & $0.71 \pm 0.01$ \\
\hline Pink Flamingo & $1.76 \pm 0.01$ & $0.22 \pm 0.01$ & $0.71 \pm 0.01$ \\
\hline Russian Black & $2.04 \pm 0.02$ & $0.09 \pm 0.01$ & $0.75 \pm 0.02$ \\
\hline Royal Harvest & $2.03 \pm 0.01$ & $0.08 \pm 0.01$ & $0.72 \pm 0.01$ \\
\hline
\end{tabular}

The complex of micromycetes under the varieties "Royal Harvest" and "Leader" had the greatest similarity with the soil of the control $(\mathrm{Ci}=48.28)$. The lower the similarity value, the greater the difference is observed between soil complexes. This means that the plants of the varieties "Royal Harvest" and "Leader" had the least influence. The degree of similarity at the level of 56\% and 50\% was found in pairs of varieties "Belorusskie" and "Russian black", "Royal Harvest" and "Bobchinskie", respectively. Thus, the species composition and structure of the soil mycocomplexes of the studied $V$. faba cultivars were different. The number of micromycetes in the rhizosphere is significantly (by $12.5 \pm 2.3$ thousand CFU / $g$ soil) higher than in the control soil. In the complex of micromycetes under beans, the proportion of typical species increased by $8-47 \%$ and their abundance increased by $4-28 \%$ compared to the control soil. The degree of similarity of the complexes of micromycetes of leguminous soils with the control soil was $20-60 \%$.

In the soil mycocomplexes of each cultivar, there were specific groups of micromycetes with a different composition of typical and random species. The greatest species diversity was found in the "Bobchinskie" and "Velena" varieties. Phytopathogenic fungi A. fabae, $C$. herbarum, and $U$. botrytis were present only in the rank of random species in mycocomplexes under some cultivars. From the genus Fusarium, phytopathogenic fungi, which are dangerous for beans, were found in the composition of typical species under all studied varieties.

\section{References}

1. S. Multari, D. Stewart, R. Wendy. Comprehensive Reviews in Food Science and Food Safety. 14 (2015)

2. C. Helstosky. Food culture in the Mediterranean. London, 199 (2009)

3. A. Singh, R.C. Bharati, N. Manibhushan, A. Pedpati. African Journal of Agricultural. 8, 50 (2013)

4. A.K. Singh, B.P. Bhatt. Faba Bean (Vicia faba L.): A potential leguminous crop of India. (Singh, Patna, 2012) 
5. E. Skrzypek, I. Czyczyło-Mysza, I. Marcińska, Acta Biologica Cracoviensia. Series Batanica. 54, 2 (2012)

6. Yu.N. Kurkina, Nguyen Thi Lan Huong. Problems of Regional Ecology, 2 (2015)

7. Yu.N. Kurkina. Vegetables of Russia. 6, 44 (2018)

8. L. Wolfgang, H. Moemen, M. Nenad, J. HansJörg, J. Srecko Faba bean Compendium of transgenic crop plants: Transgenic Legume grains and forages (2008)

9. B.A. Dospekhov. Field experiment methodology (with the basics of statistical processing of research results) (1985)

10. D.G. Zvyagintsev. Methods of Soil Microbiology and Biochemistry (1991)

11. W. Gerlach, H.I. Nirenberg The genus Fusarium - a pictorial atlas. Mitteilungen aus der Biologischen Bundesanstalt fur Land-und Forstwirtschaft Berlin-Dahlem (1982)

12. J.F. Leslie, B.A. Summerell. The Fusarium Laboratory Manual. (Ames, IA, USA: Blackwell Publishing Professional, 2006)

13. J.C. Zak, M.R. Willig. Fungal biodiversity patterns. In: Biodiversity of fungi. Inventory and monitoring methods (USA: Elsevier Academic Press, 2004)

14. E.C. Pielou Ecological Diversity (New York: Wiley Interscience, 1975) 